\title{
Determination of the prognostic value of preoperative CA15-3 and CEA in predicting the prognosis of young patients with breast cancer
}

\author{
XUAN LI* ${ }^{*}$, DANIAN DAI ${ }^{*}$, BO CHEN ${ }^{*}$, HAILIN TANG, XIAOMING XIE and WEIDONG WEI \\ Department of Breast Oncology, Sun Yat-sen University Cancer Center, State Key Laboratory of \\ Oncology in South China, Collaborative Innovation Center for Cancer Medicine, Guangzhou, Guangdong 510060, P.R. China
}

Received August 12, 2017; Accepted December 7, 2017

DOI: $10.3892 / \mathrm{ol} .2018 .9160$

\begin{abstract}
To the best of our knowledge, no previous study has investigated the association of carcinoembryonic antigen (CEA) and cancer antigen 15-3 (CA15-3) with the prognosis for young patients ( $\leq 40$ years) with breast cancer. In the present study, preoperative CEA and CA15-3 serum levels were evaluated in the prediction of the prognosis for young patients with breast cancer. In total, 699 patients were recruited, for which the CEA and CA15-3 serum levels had been measured prior to surgery via a blood sample. The optimal cut-off high and low values were determined using receiver operating characteristic curve analysis and Youden's index. The value of CEA and CA15-3 in predicting overall survival (OS) and disease-free survival (DFS) were measured using univariate and multivariate Cox's regression analyses. The cut-off values were $3.38 \mathrm{ng} / \mathrm{ml}$ and $12.32 \mathrm{U} / \mathrm{ml}$ for CEA and CA15-3, respectively. It was identified that CEA, but not CA15-3, was a predictor for the prognosis of the young patients with breast cancer. Multivariate analysis confirmed that CEA, but not CA15-3, was an independent prognostic marker for all young patients with breast cancer. In total, 623 young patients exhibited decreased levels of CEA; in these patients, CA15-3 with a cut-off value of $12.48 \mathrm{U} / \mathrm{ml}$ was an independent prognostic factor for OS and DFS. Preoperative serum CEA may thus serve as an independent predictor of poor prognosis for young patients with
\end{abstract}

Correspondence to: Professor Weidong Wei or Professor Xiaoming Xie, Department of Breast Oncology, Sun Yat-sen University Cancer Center, State Key Laboratory of Oncology in South China, Collaborative Innovation Center for Cancer Medicine, 651 Dongfeng East Road, Guangzhou, Guangdong 510060, P.R. China

E-mail: wwdzsdx@foxmail.com

E-mail: xiexm@sysucc.org.cn

${ }^{*}$ Contributed equally

Key words: breast cancer, tumor markers, carcinoembryonic antigen, cancer antigen 15-3, prognostic factors breast cancer. However, for low-risk patients with decreased CEA levels, serum CA15-3 may supplement the prediction of overall prognosis.

\section{Introduction}

Breast cancer has the highest incidence rate in women, and has increased steadily in incidence in China in recent years (1-4). Young patients ( $\leq 40$ years) are estimated to account for $\sim 6-7 \%$ of all patients with breast cancer (5). The biological and clinical characteristics of breast cancer between younger and older patients vary. For example, breast cancer in younger patients typically exhibits the following features: More malignant in nature, usually diagnosed at advanced tumor stage, increased tumor grade, larger tumor size and higher lymph node-positive rates, compared with older patients (6-9). Therefore, prediction methods and treatment strategies for patients with breast cancer should be altered according to the age of the patient. Identifying the most comprehensive and credible prognostic factors to assist in decision-making for young patients with breast cancer is essential in improving the impact of therapy.

Currently, the most commonly used pathological factors include tumor size, lymph node status, tumor grade, and estrogen receptor (ER), progesterone receptor (PR) and human epidermal growth factor receptor-2 (HER-2) status $(10,11)$. Serum tumor markers have attracted increasing attention for their use in the screening and monitoring of different types of cancer. Among several tumor markers, CEA and CA15-3 are the two most widely used for breast cancer. Numerous studies have been performed to quantitatively evaluate the serum levels of these two tumor markers, which have identified a wide range of cut-off values for predicting the prognosis of poor survival in breast cancer (12-21). At present, the predictive abilities of CEA and CA15-3 remain unclear. Ebeling et al (22) investigated 1,046 patients with breast cancer and identified via multivariate analysis that CA15-3 was not a predictor for poor outcome; however, as reviewed by Duffy (23), increased CA15-3 may be associated with a poor outcome in patients with breast cancer. Despite CEA exhibiting a lower positive rate (positive CEA values ranged from 1.99-10 ng/ml, and positive CEA levels ranged from 7.1-36\%) in breast cancer, 
there are fewer large-scale studies investigating its prognostic ability (12,24-27).

To the best of our knowledge, no previous studies have demonstrated any potential prognostic values of CEA and CA15-3 in young patients with breast cancer. In the present study, clinicopathological data and preoperative serum CEA and CA15-3 levels of young patients with breast cancer were retrospectively analyzed in order to explore whether these tumor markers could be used to predict the prognosis of patients with breast cancer. Furthermore, the associations between clinicopathological parameters and these two tumor markers were also analyzed.

\section{Patients and methods}

Study population. All patients in the retrospective study were treated between January 2008 and December 2012 at the Sun Yat-Sen University Cancer Center (Guangzhou, China) and were diagnosed with invasive breast cancer. Patient data collected for the present study included clinicopathological information, treatment modalities and details of patient outcome. The inclusion criteria for the study were as follows: i) Invasive breast cancer defined using histological examination; ii) no other types of cancer diagnosed or serious disease prior to diagnosis; iii) non-metastatic breast cancer at the time of diagnosis; iv) patients received surgery which completely removed the tumor; v) available and complete clinicopathological and follow-up data; vi) testing of CEA and CA15-3 levels prior to surgery; and vii) no neoadjuvant chemotherapy or radiotherapy prior to surgery. Patients with stage IV tumors or carcinoma in situ without invasive lesions were excluded.

Clinical data collection. Basic characteristics collected included age, surgery method, tumor size, axillary lymph node status, and ER, PR and HER-2 status. Tumor-node-metastasis (TNM) staging was based on the American Joint Committee on Cancer criteria, 7th edition (28). The disease subtypes were defined as follows: Luminal A (ER and/or PR-positive, HER-2-negative and Ki-67<14\%), luminal B (ER and/or PR-positive alone with HER-2-positive or Ki-67>14\%), HER-2 overexpressing (ER and PR all negative, HER-2-positive) and triple-negative breast cancer (ER, PR and HER-2-negative). HER-2 positivity was defined as $3^{+}$in immunohistochemical tests, which were performed using a polyclonal human c-erbB-2/neu antibody, and $>30 \%$ of the tumor cells were stained (29). Fluorescence in situ hybridization (FISH) tests were performed to determine the status of the HER-2 gene when the immunohistochemical score was $2^{+}$(immunohistochemistry demonstrated $10-30 \%$ tumor cell staining) according to a protocol described previously (30). If a FISH test was not performed, the cases of $2^{+}$were regarded as missing data. A complete blood count and levels of CEA and CA15-3 tumor markers were performed as part of the routine clinical evaluation prior to surgery.

Study endpoints. The first day of follow-up was considered as the day of confirmed pathological diagnosis. The follow-up consisted of the reexamination of records or phone calls, and included medical history, physical and laboratory examinations, and radiological imaging tests to detect metastasis or relapse. Overall survival (OS) was calculated as from the day of pathological confirmation to the day of the follow-up endpoint or mortality from any cause. Disease-free survival (DFS) was calculated as from the time of pathological confirmation to the time of first recurrence (local recurrence, distant metastasis or patient mortality).

Statistical analyses. Comparisons between different variables were made using Pearson's $\chi^{2}$-square test or Fisher's exact test. The clinical significance and the optimal cut-off value of CEA and CA15-3 were determined using ROC curve analysis. The highest Youden's index was used to stratify patients into 2 ranges according to the cut-off value. The OS and DFS were determined using the Kaplan-Meier method and log-rank test. The influence of potential factors on OS and DFS were determined using univariate and multivariate Cox proportional hazards analyses. The relative risk of each factor was demonstrated using hazard ratios (HRs) and 95\% corresponding confidence intervals (CIs). Significance in univariate analyses was regarded as $\mathrm{P}<0.1$, whereas $\mathrm{P}<0.05$ was considered to indicate a statistically significant difference for other results. All statistical analyses were performed using SPSS version 20.0 (IBM Corp., Armonk, NY, USA).

\section{Results}

Patient characteristics. In total, out of 699 cases in the present retrospective study, 81 (11.6\%) patients were 20-30 years, $181(25.9 \%)$ patients were 30-35 years and $437(62.5 \%)$ patients were 35-40 years at the time of the histopathological diagnosis of invasive breast cancer. The median age of the patients was 36 . The basic clinicopathological characteristics are presented in Table I. The mean follow-up time was 56 months. The number of patients with stage I, II and III tumors were 239 (34.2\%), $308(44.1 \%)$ and $152(21.7 \%)$, respectively. Among all cases, the identified sub-types were luminal A $(134,19.2 \%)$, luminal B $(364,52.1 \%)$, triple-negative $(89,12.7 \%)$, HER2-positive $(78,11.1 \%)$ and unknown type $(34,4.9 \%)$.

Optimal cut-off values for CEA and CA15-3. The optimal cut-off values for CEA and CA15-3 were determined using ROC curve analysis (Fig. 1). The areas under the curves (AUCs) for CEA and CA15-3 were $0.695(\mathrm{P}<0.001)$ and $0.531(\mathrm{P}=0.504)$, respectively, for all patients. Using the highest Youden's index value, the cut-off values for CEA and CA15-3 were set as $3.38 \mathrm{ng} / \mathrm{ml}$ and $12.31 \mathrm{U} / \mathrm{ml}$, respectively. Patients were stratified into 2 levels (low-CEA and high-CEA or low-CA15-3 and high-CA15-3) according to their respective cut-off values: $76(10.9 \%)$ of the patients exhibited high CEA, and 623 (89.1\%) low CEA; 295 (42.2\%) of the patients exhibited high CA15-3 and 404 (57.8\%) low CA15-3.

The associations between CEA or CA153 with clinicopathological characteristics are presented in Table I. CEA was significantly associated with the surgery method $(\mathrm{P}=0.032)$, TNM stage $(\mathrm{P}=0.079)$, tumor size $(\mathrm{P}<0.001)$, axillary lymph node status $(\mathrm{P}=0.001)$ and HER-2 status $(\mathrm{P}=0.004)$. However, 
Table I. Association of clinicopathological characteristics with CEA and CA15-3 level in young patients with breast cancer.

\begin{tabular}{|c|c|c|c|c|c|c|}
\hline \multirow[b]{2}{*}{ Variables } & \multicolumn{2}{|c|}{ CEA, n (\%) } & \multirow[b]{2}{*}{ P-value } & \multicolumn{2}{|c|}{ CA15-3, n (\%) } & \multirow[b]{2}{*}{ P-value } \\
\hline & Low & High & & Low & High & \\
\hline Age, years & & & 1.000 & & & 0.752 \\
\hline$\leq 35$ & $234(89.3)$ & $28(10.7)$ & & $149(56.9)$ & $113(43.1)$ & \\
\hline$>35$ & $389(89.0)$ & $48(11.0)$ & & $255(58.4)$ & $182(41.6)$ & \\
\hline Surgical option & & & 0.032 & & & 0.151 \\
\hline Modified radical mastectomy & $492(87.9)$ & $68(12.1)$ & & $316(56.4)$ & $244(43.6)$ & \\
\hline Conserving surgery & $131(94.2)$ & $8(5.8)$ & & $88(63.3)$ & $51(36.7)$ & \\
\hline Tumor stage & & & $<0.001$ & & & 0.022 \\
\hline $\mathrm{T} 1$ & $312(91.2)$ & $30(8.8)$ & & $208(60.8)$ & $134(39.2)$ & \\
\hline $\mathrm{T} 2$ & $280(90.0)$ & $31(10.0)$ & & $178(57.2)$ & $133(42.8)$ & \\
\hline $\mathrm{T} 3$ & $15(60.0)$ & $10(40.0)$ & & $12(48.0)$ & $13(52.0)$ & \\
\hline $\mathrm{T} 4$ & $16(76.2)$ & $5(23.8)$ & & $6(28.6)$ & $15(71.4)$ & \\
\hline Lymph node metastasis & & & 0.001 & & & 0.050 \\
\hline No & $348(92.3)$ & $29(7.7)$ & & $231(61.3)$ & $146(38.7)$ & \\
\hline N1 & $155(86.1)$ & $25(13.9)$ & & $105(58.3)$ & $75(41.7)$ & \\
\hline $\mathrm{N} 2$ & 77 (90.6) & $8(9.4)$ & & $42(49.4)$ & $43(50.6)$ & \\
\hline N3 & $43(75.4)$ & $14(24.6)$ & & $26(45.6)$ & $31(54.4)$ & \\
\hline TNM stage & & & 0.079 & & & 0.036 \\
\hline I & $218(91.2)$ & $21(8.8)$ & & $145(60.7)$ & $94(39.3)$ & \\
\hline II & 277 (89.9) & $31(10.1)$ & & $185(60.1)$ & $123(39.9)$ & \\
\hline III & $128(84.2)$ & $24(15.8)$ & & $74(48.7)$ & $78(51.3)$ & \\
\hline ER & & & 0.595 & & & 1.000 \\
\hline Positive & $444(89.5)$ & $52(10.5)$ & & $287(57.9)$ & $209(42.1)$ & \\
\hline Negative & $179(88.2)$ & $24(11.8)$ & & $117(57.6)$ & $86(42.4)$ & \\
\hline PR & & & 0.793 & & & 0.455 \\
\hline Positive & $431(88.9)$ & $54(11.1)$ & & $285(58.8)$ & $200(41.2)$ & \\
\hline Negative & $192(89.7)$ & $22(10.3)$ & & $119(55.6)$ & $95(44.4)$ & \\
\hline HER-2 & & & 0.004 & & & 0.053 \\
\hline Positive & $173(84.0)$ & $33(16.0)$ & & $107(51.9)$ & $99(48.1)$ & \\
\hline Negative & $439(91.8)$ & $39(8.2)$ & & $287(60.0)$ & $191(40.0)$ & \\
\hline Intrinsic subtypes & & & 0.115 & & & 0.376 \\
\hline Luminal A & $126(94.0)$ & $8(6.0)$ & & $83(61.9)$ & $51(38.1)$ & \\
\hline Luminal B & $318(87.4)$ & $46(12.6)$ & & $204(56.0)$ & $160(44.0)$ & \\
\hline Triple-negative & $83(93.3)$ & $6(6.7)$ & & $48(53.9)$ & $41(46.1)$ & \\
\hline HER-2 overexpression & $67(85.9)$ & $11(14.1)$ & & $45(57.7)$ & $33(42.3)$ & \\
\hline Missing data & $29(85.3)$ & $5(14.7)$ & & $24(70.6)$ & $10(29.4)$ & \\
\hline Adjuvant chemotherapy & & & 0.472 & & & 0.980 \\
\hline Yes & $563(89.1)$ & $69(10.9)$ & & $366(57.9)$ & $266(42.1)$ & \\
\hline No & $53(91.4)$ & $5(8.6)$ & & $33(56.9)$ & $25(43.1)$ & \\
\hline Missing data & $7(77.8)$ & $2(22.2)$ & & $5(55.6)$ & $4(44.4)$ & \\
\hline Adjuvant radiotherapy & & & 0.222 & & & 0.973 \\
\hline Yes & $214(91.5)$ & $20(8.5)$ & & $134(57.3)$ & $100(42.7)$ & \\
\hline No & $362(87.4)$ & $52(12.6)$ & & $240(58.0)$ & $174(42.0)$ & \\
\hline Missing data & $47(92.2)$ & $4(7.8)$ & & $30(58.9)$ & $21(41.1)$ & \\
\hline Endocrine therapy & & & 0.503 & & & 0.151 \\
\hline Yes & $439(88.3)$ & $58(11.7)$ & & $296(59.6)$ & $201(40.4)$ & \\
\hline No & $124(91.9)$ & $11(8.1)$ & & $68(50.4)$ & $67(49.6)$ & \\
\hline Missing data & $60(89.6)$ & $7(10.4)$ & & $40(59.7)$ & $27(40.3)$ & \\
\hline
\end{tabular}


Table I. Continued.

\begin{tabular}{|c|c|c|c|c|c|c|}
\hline \multirow[b]{2}{*}{ Variables } & \multicolumn{2}{|c|}{ CEA, n (\%) } & \multirow[b]{2}{*}{ P-value } & \multicolumn{2}{|c|}{ CA15-3, n (\%) } & \multirow[b]{2}{*}{ P-value } \\
\hline & Low & High & & Low & High & \\
\hline Overall survival outcome & & & $<0.001$ & & & 0.034 \\
\hline Surviving & $599(91.0)$ & $59(9.0)$ & & $387(58.8)$ & $271(41.2)$ & \\
\hline Deceased & $24(58.5)$ & $17(41.5)$ & & $17(41.5)$ & $24(58.5)$ & \\
\hline
\end{tabular}

P-values were determined using the $\chi^{2}$ test. TNM, tumor-node-metastasis; ER, estrogen receptor; PR, progesterone receptor; HER-2, human epidermal growth factor receptor-2.

A

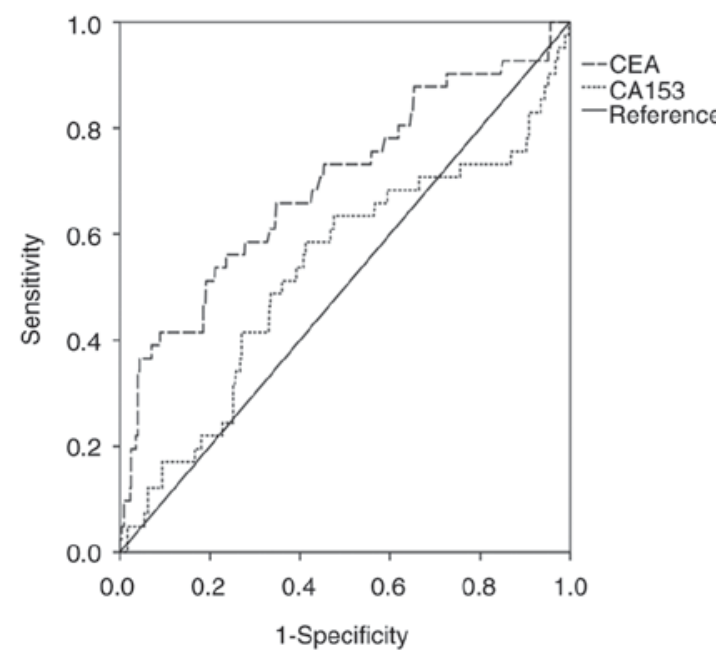

B

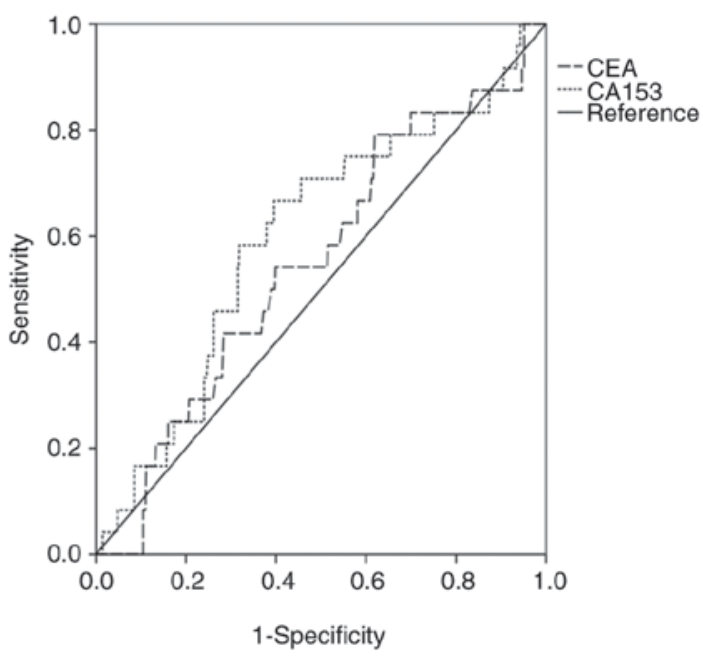

Figure 1. ROC curve for CEA and CA15-3. (A) ROC curve of CEA and CA15-3 for all patients. CEA AUC=0.695, $\mathrm{P}<0.001 ; \mathrm{CA} 15-3 \mathrm{AUC}=0.531, \mathrm{P}=0.504$ (B) ROC curve of CEA and CA15-3 in low CEA patients. CEA AUC=0.551, $\mathrm{P}=0.399$; CA15-3 AUC $=0.600$, $\mathrm{P}=0.098$. ROC, receiver operating characteristic; CEA, carcinoembryonic antigen; CA, cancer antigen; AUC, area under the curve.

CEA was not significantly associated with ER status, PR status, molecular sub-type or follow-up treatment method (all $\mathrm{P}>0.05$; Table I). CA153 was only significantly associated with TNM stage $(\mathrm{P}=0.036)$ and tumor size $(\mathrm{P}=0.022)$. From the 623 low patients with CEA, the AUCs for CEA and CA15-3 were 0.551 $(\mathrm{P}=0.399)$ and $0.600(\mathrm{P}=0.098)$, respectively, and the cut-off values were $1.085 \mathrm{ng} / \mathrm{ml}$ and $12.48 \mathrm{U} / \mathrm{ml}$.

Association between CEA or CA15-3 and survival outcomes in all young patients with breast cancer. In the present study, the OS rate was $94.1 \%$ and the DFS rate was $82.4 \%$ for all patients. As demonstrated by the Kaplan-Meier curves, high CEA and CA15-3 were associated with poor OS and DFS in the young patients with breast cancer (Fig. 2). Univariate analysis indicated that patient OS may have been associated with age, surgical method, TNM stage, ER, CEA and CA15-3 levels $(\mathrm{P}<0.1)$. Multivariate analysis indicated that $\mathrm{CEA}$ was an independent prognostic factor for OS $(\mathrm{P}<0.001)$ with a HR of 2.732 (95\% CI, 1.792-4.164). Other identified prognostic factors for OS included age, ER status and TNM stage (Table II). Univariate analysis revealed that DFS was associated with age, TNM stage, CEA and CA15-3 levels $(\mathrm{P}<0.1)$. Multivariate analysis identified that CEA and TNM stage were independent prognostic factors for DFS (Table II). However, CA15-3 was not an independent prognostic marker for OS or DFS in the multivariate analysis (Table II).

Association between CA15-3 and survival outcomes in low-CEA patients. The 623 patients with low CEA had an OS rate of $96.1 \%$ and a DFS rate of $84.8 \%$. As demonstrated with Kaplan-Meier curves, high CA15-3 within the low CEA group was associated with poor OS and DFS. Relatively high CEA was associated with DFS, and not with OS, in the low-CEA young breast cancer patients (Fig. 3). Furthermore, a univariate analysis demonstrated that $\mathrm{OS}$ in this group was associated with age, TNM stage, PR, CEA and CA15-3 levels $(\mathrm{P}<0.1)$. Multivariate analysis demonstrated that age, TNM stage, PR and CA15-3 levels were independent prognostic factors for OS in this group $(\mathrm{P}<0.05)$. Multivariate analysis for DFS demonstrated that TNM stage and CA15-3 were independent predictive markers (Table III).

\section{Discussion}

A definitive definition for young patients with breast cancer remains controversial. Based on a search of the MEDLINE 
A

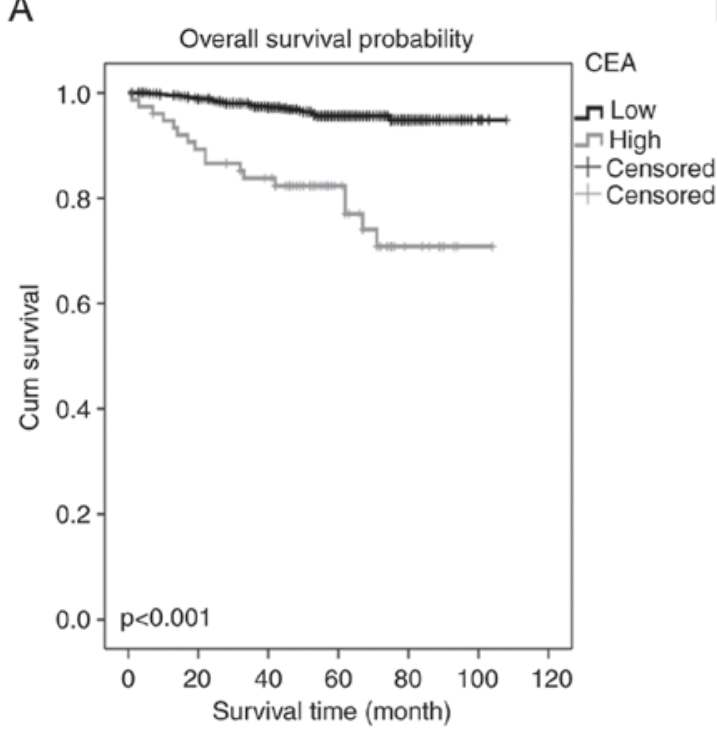

C

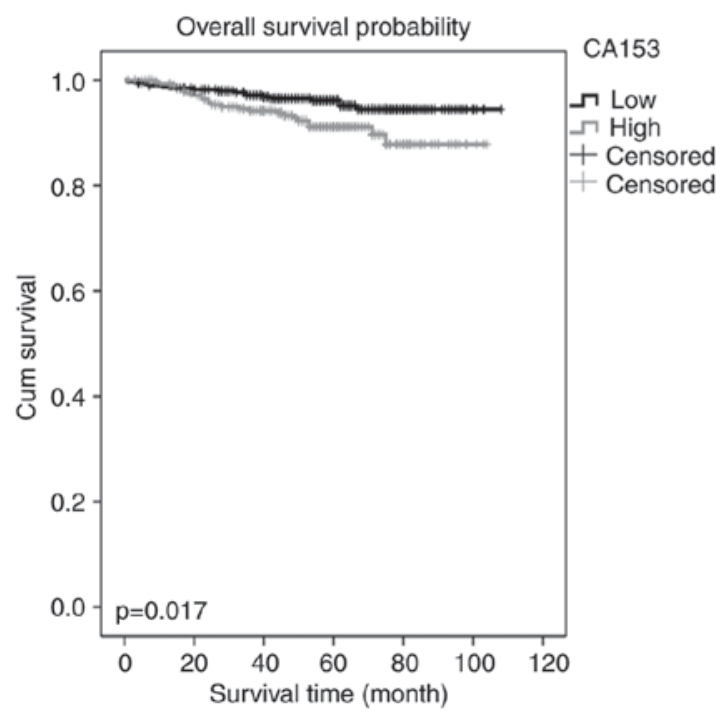

B

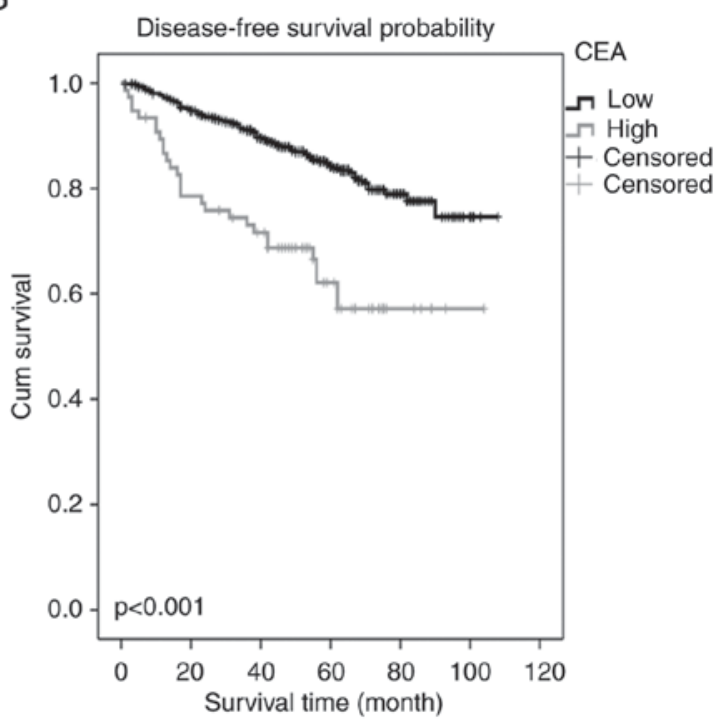

D

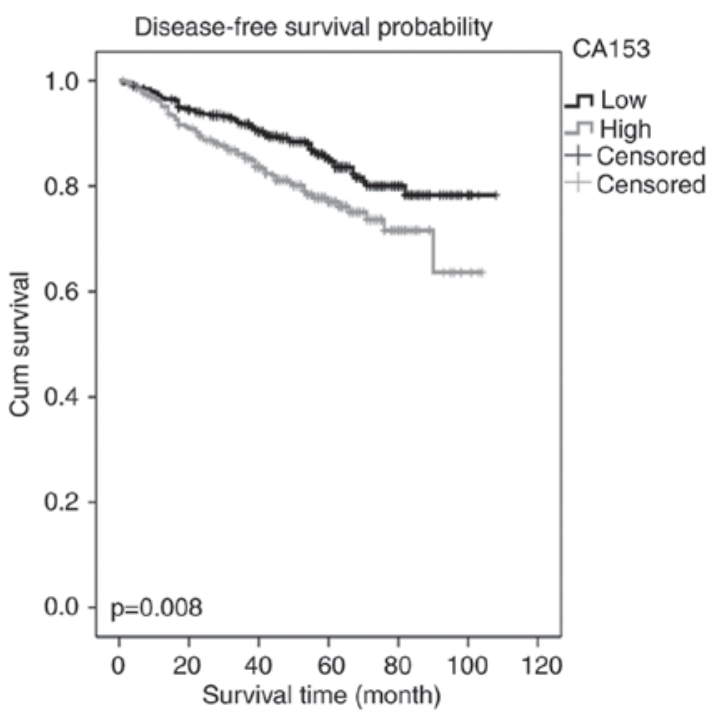

Figure 2. Kaplan-Meier estimator curves of survival rates for young patients with breast cancer. (A) Overall survival and (B) disease-free survival for the young patients with breast cancer stratified by the CEA cut-off level. (C) Overall survival and (D) disease-free survival for all young patients with breast cancer according to the CA15-3 cut-off level. CEA, carcinoembryonic antigen; CA, cancer antigen.

and Cancer Lit databases for the definition of 'young age' in breast cancer, one study defined this as between 35 and 40 years of age (31). Other studies defined young patients with breast cancer as $<40$ years of age $(8,9,32-34)$. Despite recent improvements in cancer treatment, the OS and DFS rates for younger patients ( $\leq 40$ years) are markedly lower than for older patients ( $>40$ years) with breast cancer (35). This is potentially due to differences in the biological and physiological parameters of the disease, including the increased likelihood of aggressive subtypes of breast cancer in younger patients $(33,36)$. Despite these differences, the standard treatment is similar for both young and old breast cancer patients. In the present study, patients that were aged $\leq 40$ years were considered 'young patients'. The median age of the 699 patients included in the present study was 36 years. However, it is notable that previous studies which divided patients into groups $<35$ years and $>35$ years demonstrated that age had no predictive value for OS and DFS $(21,35)$. Despite this, in the present study, multivariate analysis identified that age had independent prognostic value for OS. Consequently, as age may be an independent prognostic marker, breast cancer in young patients may potentially be regarded as a separate disease subtype.

Blood samples were obtained from each patient prior to surgery to test CEA and CA15-3 levels. CEA and CA15-3 are the most investigated tumor markers in breast cancer, and when the acquisition of tissue specimens is not possible, these markers may offer useful information about the disease phenotype in the early stages (13). However, their sensitivity and specificity may differ according to the cut-off value used. In our hospital (Sun Yat-sen University Cancer Center), the cut-off values for CEA and CA15-3 are usually $5 \mathrm{ng} / \mathrm{ml}$ and $25 \mathrm{U} / \mathrm{ml}$, respectively; these cut-off values are the most commonly used $(21,37)$. The value of tumor markers varies 
Table II. Univariate and multivariate analysis of factors for OS and DFS in all patients.

A, Association of factors with OS

\begin{tabular}{|c|c|c|c|c|}
\hline \multirow[b]{2}{*}{ Variable } & \multicolumn{2}{|c|}{ Univariate } & \multicolumn{2}{|c|}{ Multivariate } \\
\hline & $\operatorname{HR}(95 \% \mathrm{CI})$ & P-value & $\operatorname{HR}(95 \% \mathrm{CI})$ & P-value \\
\hline Age (>35/ $\leq 35$ years) & $0.457(0.246-0.846)$ & 0.013 & $0.403(0.215-0.775)$ & 0.005 \\
\hline $\begin{array}{l}\text { Surgical option (conserving surgery/ } \\
\text { modified radical mastectomy) }\end{array}$ & $0.321(0.099-1.041)$ & 0.058 & $0.572(0.170-1.921)$ & 0.366 \\
\hline \multicolumn{5}{|l|}{ TNM stage } \\
\hline $\mathrm{I}$ & 1 (reference) & & 1 (reference) & \\
\hline II & $4.281(1.247-14.692)$ & 0.021 & $3.960(1.152-13.616)$ & 0.029 \\
\hline III & $13.297(3.978-44.443)$ & $<0.001$ & $11.026(3.219-37.771)$ & $<0.001$ \\
\hline $\operatorname{ER}(-/+)$ & $1.821(0.978-3.391)$ & 0.059 & $2.415(1.272-4.588)$ & 0.007 \\
\hline $\operatorname{PR}(-/+)$ & $1.416(0.749-2.675)$ & 0.284 & & \\
\hline HER-2 (-/+) & $0.648(0.343-1.226)$ & 0.182 & & \\
\hline CEA (high/low) & $6.128(3.291-11.409)$ & $<0.001$ & $4.962(2.647-9.302)$ & $<0.001$ \\
\hline CA15-3 (high/low) & $2.100(1.127-3.911)$ & 0.019 & $1.765(0.930-3.351)$ & 0.082 \\
\hline
\end{tabular}

B, Association of factors with DFS

\begin{tabular}{|c|c|c|c|c|}
\hline \multirow[b]{2}{*}{ Variable } & \multicolumn{2}{|c|}{ Univariate } & \multicolumn{2}{|c|}{ Multivariate } \\
\hline & HR $(95 \%$ CI $)$ & P-value & HR $(95 \%$ CI $)$ & P-value \\
\hline Age $(>35 / \leq 35$ years $)$ & $0.728(0.510-1.039)$ & 0.08 & $0.702(0.491-1.003)$ & 0.052 \\
\hline $\begin{array}{l}\text { Surgical option (conserving surgery/ } \\
\text { modified radical mastectomy) }\end{array}$ & $0.800(0.495-1.292)$ & 0.361 & & \\
\hline \multicolumn{5}{|l|}{ TNM stage } \\
\hline $\mathrm{I}$ & 1 (reference) & & 1 (reference) & \\
\hline II & $1.290(0.805-2.068)$ & 0.29 & $1.236(0.771-1.983)$ & 0.379 \\
\hline III & $3.440(2.164-5.468)$ & $<0.001$ & $3.206(1.945-4.960)$ & $<0.001$ \\
\hline $\mathrm{ER}(-/+)$ & $1.268(0.869-1.849)$ & 0.218 & & \\
\hline $\mathrm{PR}(-/+)$ & $1.119(0.763-1.642)$ & 0.565 & & \\
\hline HER-2 (-/+) & $0.785(0.536-1.149)$ & 0.214 & & \\
\hline CEA (high/low) & $2.732(1.792-4.164)$ & $<0.001$ & $2.451(1.599-3.756)$ & $<0.001$ \\
\hline CA15-3 (high/low) & $1.608(1.129-2.291)$ & 0.009 & $1.389(0.970-1.988)$ & 0.073 \\
\hline
\end{tabular}

depending on the molecular sub-group. To determine the cut-off value with the strongest prognostic ability, several different cut-off values have previously been applied for CEA (2-10 ng/ml) and CA15-3 (21.8-60 U/ml) (12,14,18,38-41). In the present study, CEA and CA15-3 were identified as prognostic predictors for young patients with breast cancer according to ROC curve analysis. Multivariate analysis revealed that CA15-3 was not an independent prognostic factor, whereas CEA could independently predict the prognosis. These results differ from previous studies that have identified CA15-3 as an independent prognostic marker for breast cancer $(19,21,37)$. This difference may be due to the relatively powerful prognostic ability of CEA in young patients with breast cancer, or because CEA and CA15-3 have a strong collinear association in young patients with breast cancer that influences the predictive function of CA15-3.

Based on the highest Youden's index value, the present study selected $3.38 \mathrm{ng} / \mathrm{ml} \mathrm{CEA}$ and $12.31 \mathrm{U} / \mathrm{ml} \mathrm{CA} 15-3$ as the optimal cut-off values. These cut-offs were more 
Table III. Univariate and multivariate analysis.

A, Association of factors with OS

\begin{tabular}{|c|c|c|c|c|}
\hline \multirow[b]{2}{*}{ Variable } & \multicolumn{2}{|l|}{ Univariate } & \multicolumn{2}{|l|}{ Multivariate } \\
\hline & $\mathrm{HR}(95 \% \mathrm{CI})$ & P-value & $\mathrm{HR}(95 \% \mathrm{CI})$ & P-value \\
\hline $\operatorname{Age}(>35 / \leq 35$ years $)$ & $0.358(0.157-0.819)$ & 0.015 & $0.303(0.131-0.701)$ & 0.005 \\
\hline $\begin{array}{l}\text { Surgical option (conserving surgery/ } \\
\text { modified radical mastectomy) }\end{array}$ & $0.339(0.080-1.443)$ & 0.143 & & \\
\hline \multicolumn{5}{|l|}{ TNM stage } \\
\hline I & 1 (reference) & & 1 (reference) & \\
\hline II & $9.086(1.173-70.380)$ & 0.035 & $8.855(1.140-68.765)$ & 0.037 \\
\hline III & $23.040(2.995-177.235)$ & 0.003 & $25.538(3.292-198.121)$ & 0.002 \\
\hline $\operatorname{ER}(-/+)$ & $1.8982(0.840-4.262)$ & 0.124 & & \\
\hline PR (-/+) & $2.068(0.925-4.622)$ & 0.077 & $2.445(1.086-5.507)$ & 0.031 \\
\hline HER-2 (-/+) & $0.681(0.291-1.595)$ & 0.377 & & \\
\hline CEA (high/low) ${ }^{\mathrm{a}}$ & $2.332(0.871-6.246)$ & 0.092 & $2.316(0.853-6.287)$ & 0.099 \\
\hline CA15-3 (high/low) ${ }^{\mathrm{a}}$ & $3.143(1.345-7.347)$ & 0.008 & $2.970(1.263-6.986)$ & 0.013 \\
\hline
\end{tabular}

B, Association of factors with DFS

\begin{tabular}{|c|c|c|c|c|}
\hline \multirow[b]{2}{*}{ Variable } & \multicolumn{2}{|c|}{ Univariate } & \multicolumn{2}{|c|}{ Multivariate } \\
\hline & HR $(95 \%$ CI $)$ & P-value & HR $(95 \%$ CI) & P-value \\
\hline Age $(>35 / \leq 35$ years $)$ & $0.807(0.537-1.213)$ & 0.302 & & \\
\hline $\begin{array}{l}\text { Surgical option (conserving surgery/ } \\
\text { modified radical mastectomy) }\end{array}$ & $0.900(0.539-1.504)$ & 0.688 & & \\
\hline \multicolumn{5}{|l|}{ TNM stage } \\
\hline I & 1 (reference) & & 1 (reference) & \\
\hline II & $1.356(0.797-2.305)$ & 0.261 & $1.326(0.779-2.255)$ & 0.298 \\
\hline III & $3.442(2.029-5.839)$ & $<0.001$ & $3.196(1.879-5.435)$ & $<0.001$ \\
\hline $\mathrm{ER}(-/+)$ & $1.189(0.768-1.840)$ & 0.438 & & \\
\hline $\mathrm{PR}(-/+)$ & $1.238(0.806-1.904)$ & 0.330 & & \\
\hline HER-2 (-/+) & $0.866(0.551-1.361)$ & 0.532 & & \\
\hline CEA (high/low) ${ }^{\mathrm{a}}$ & $1.625(1.040-2.539)$ & 0.033 & $1.471(0.940-2.302)$ & 0.091 \\
\hline CA15-3 (high/low) ${ }^{\text {a }}$ & $1.753(1.171-2.623)$ & 0.006 & $1.635(1.092-2.449)$ & 0.017 \\
\hline
\end{tabular}

selective than the $5 \mathrm{ng} / \mathrm{ml}$ for CEA and $25 \mathrm{U} / \mathrm{ml}$ for CA15-3 typically used for breast cancer. This may be because only primary early stage (I-III) patients were included; CEA and CA15-3 levels may increase significantly in metastatic or recurrent breast cancer $(24,42-44)$. Therefore, in order to get the best predictive value, it may be necessary to use different cut-off values of these markers depending on the TNM stage. The multivariate analysis conducted in the present study revealed that CEA was an independent predictor for OS and
DFS for all included patients. The present study categorized patients into low or high CEA groups, and demonstrated that patients in the high CEA group had relatively poor outcomes.

The results regarding CA15-in the present study were similar to Ebeling et al (22), as the study also suggested that CA15-3 was not an independent prognostic factor for poor overall survival. However, in the low-CEA group, CA15-3 could independently predict the patient prognosis. Collectively, 
A

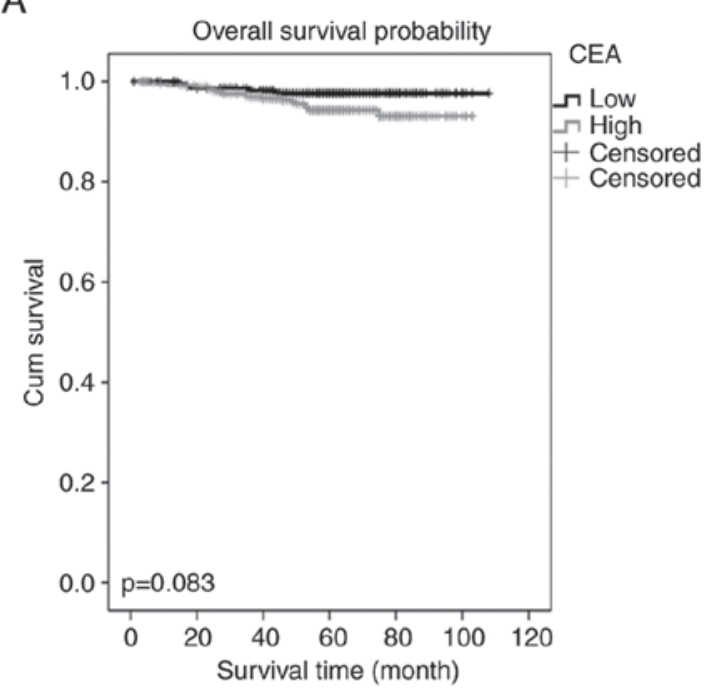

C

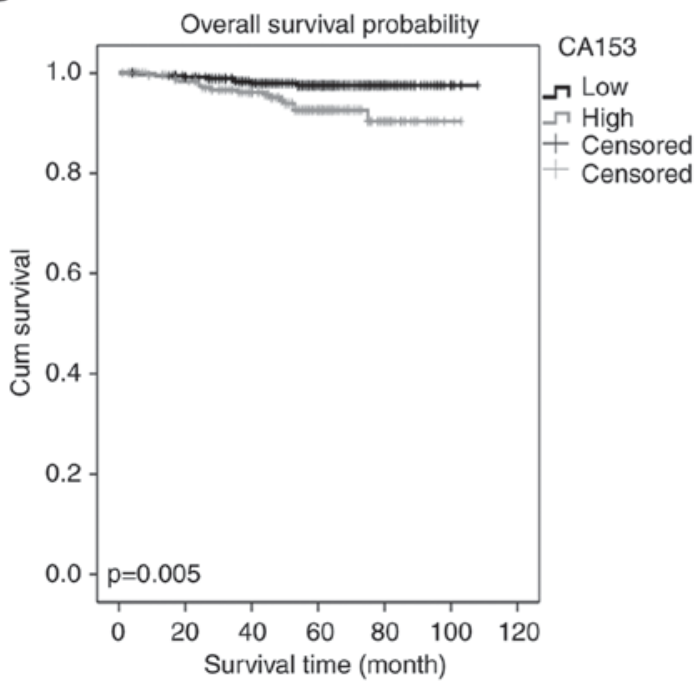

B

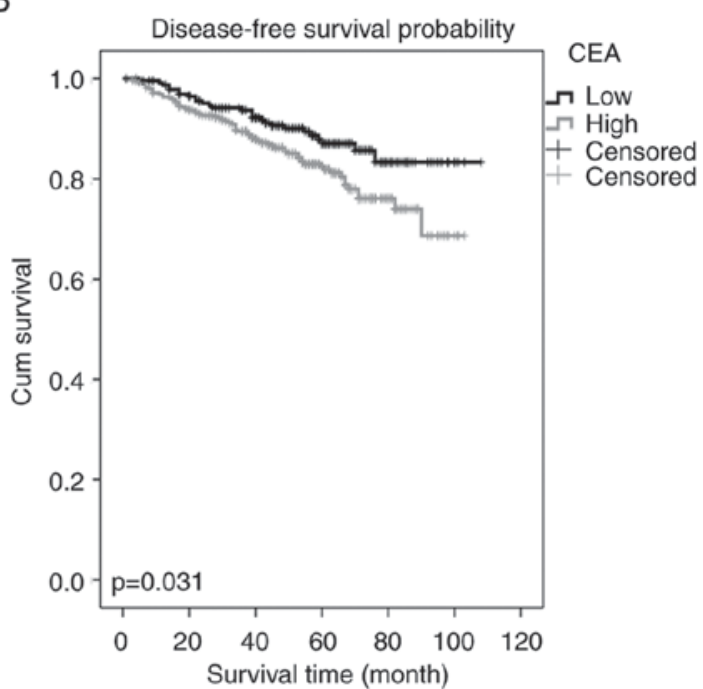

D

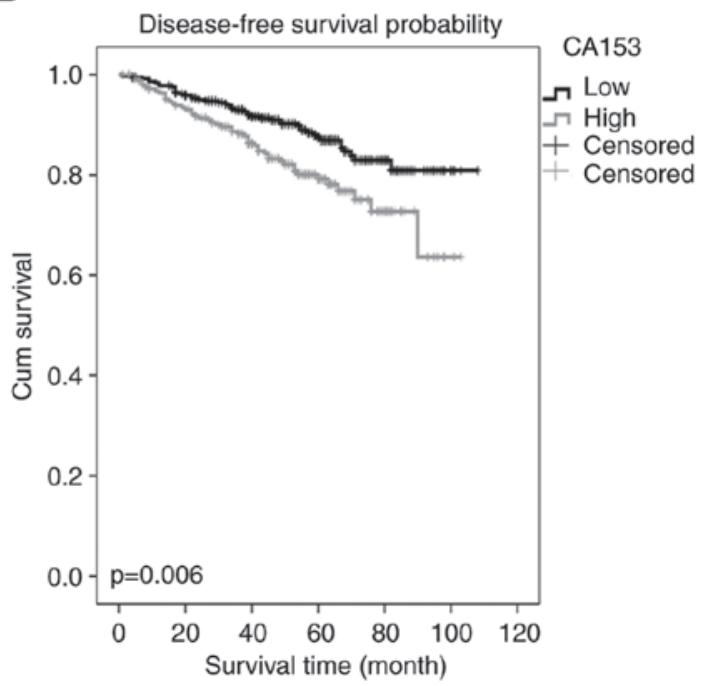

Figure 3. Kaplan-Meier estimator curves of survival rates for patients with low CEA levels. (A) Overall survival and (B) disease-free survival for the young patients with breast cancer according to the CEA cut-off level for the low CEA group. (C) Overall survival and (D) disease-free survival for the young patients with breast cancer according to the CA15-3 cut-off level for the low CEA group. CEA, carcinoembryonic antigen; CA, cancer antigen.

the data suggested that if preoperative serum CEA is elevated in young patients with breast cancer, it may not be necessary to test CA15-3 levels; however, if CEA is not elevated, the level of CA15-3 may provide additional prognostic information. These results are inconsistent with data presented by Harris et al (45), as results demonstrated that CEA may be supplementary to CA15-3.

In young patients with breast cancer, the CEA levels were decreased in patients who underwent breast-conserving surgery. This may be because conservation surgery is selected in cases with a decreased tumor burden, including a decreased tumor size and fewer metastatic lymph nodes. In the present study, patients exhibited no significant difference in adjuvant chemotherapy, radiotherapy and endocrine therapy depending on their CEA and CA15-3 levels. As preoperative levels of CEA and CA15-3 lack organ and tumor specificity, and exhibit low sensitivity, they may not be useful in guiding follow-up treatment after surgery $(45,46)$.
There were limitations to the present retrospective study. For example, it was a single-institution retrospective analysis, and despite the formulation of inclusion and exclusion criteria to minimize selective bias, it cannot be avoided completely. Furthermore, results were based on a relatively small database as it focused on a small sub-group (young patients with breast cancer) that constitutes $6-7 \%$ of all breast cancer cases. Therefore, applying the results of the present study to all patients will require further consideration.

In conclusion, the present study demonstrated that a relatively high preoperative level of CEA was an independent prognostic factor, and that relatively high CA15-3 was an independent prognostic factor in the patients with low CEA levels, by applying univariate and multivariate analyses. Combining CEA and CA15-3 with other factors may help clinicians assess the risks of metastasis and mortality after surgery in young patients with breast cancer. Further prospective studies will be essential for the validation of these results. 


\section{References}

1. Chen W, Zheng R, Zeng $\mathrm{H}$ and Zhang S: The incidence and mortality of major cancers in China, 2012. Chin J Cancer 35: 73, 2016.

2. DeSantis C, Ma J, Bryan L and Jemal A: Breast cancer statistics, 2013. CA Cancer J Clin 64: 52-62, 2014.

3. Zeng H, Zheng R, Zhang S, Zou X and Chen W: Female breast cancer statistics of 2010 in China: Estimates based on data from 145 population-based cancer registries. J Thorac Dis 6: 466-470, 2014.

4. Zhou C, He J, Li J, Fan Jh, Zhang B, Yang Hj, Xie Xm, Tang Zh, Li H, Li Jy, et al: A nation-wide multicenter 10-year (1999-2008) retrospective clinical study of endocrine therapy for Chinese females with breast cancer. PLoS One 9: e100159, 2014

5. Anders CK, Johnson R, Litton J, Phillips M and Bleyer A: Breast cancer before age 40 years. Semin Oncol 36: 237-249, 2009.

6. Anders CK, Hsu DS, Broadwater G, Acharya CR, Foekens JA, Zhang Y, Wang Y, Marcom PK, Marks JR, Febbo PG, et al: Young age at diagnosis correlates with worse prognosis and defines a subset of breast cancers with shared patterns of gene expression. J Clin Oncol 26: 3324-3330, 2008.

7. Keegan TH, DeRouen MC, Press DJ, Kurian AW and Clarke CA: Occurrence of breast cancer subtypes in adolescent and young adult women. Breast Cancer Res 14: R55, 2012.

8. Lee HB and Han W: Unique features of young age breast cancer and its management. J Breast Cancer 17: 301-307, 2014.

9. Wang K, Ren Y, Li H, Zheng K, Jiang J, Zou T, Ma B, Li H, Liu Q, Ou J, et al: Comparison of clinicopathological features and treatments between Young $(</=40$ Years) and Older $(>40$ Years $)$ female breast cancer patients in West China: A retrospective, epidemiological, multicenter, case only study. PLoS One 11: e0152312, 2016.

10. Selz J, Stevens D, Jouanneau L, Labib A and Le Scodan R: Prognostic value of molecular subtypes, ki67 expression and impact of postmastectomy radiation therapy in breast cancer patients with negative lymph nodes after mastectomy. Int J Radiat Oncol Biol Phys 84: 1123-1132, 2012.

11. Elston CW, Ellis IO and Pinder SE: Pathological prognostic factors in breast cancer. Crit Rev Oncol Hematol 31: 209-223, 1999.

12. Dai D, Chen B, Tang H, Wang B, Zhao Z, Xie X and Wei W: Nomograms for predicting the prognostic value of pre-therapeutic CA15-3 and CEA Serum Levels in TNBC patients. PLoS One 11: e0161902, 2016.

13. Di Gioia D, Dresse M, Mayr D, Nagel D, Heinemann V and Stieber P: Serum HER2 in combination with CA $15-3$ as a parameter for prognosis in patients with early breast cancer. Clin Chim Acta 440: 16-22, 2015

14. Ebeling FC, Schmitt UM, Untch M, Nagel D, Fateh-Moghadam A, Stieber P and Seidel D: Tumour markers CEA and CA 15-3 as prognostic factors in breast cancer-Univariate and multivariate analysis. Anticancer Res 19: 2545-2550, 1999.

15. Lee JS, Park S, Park JM, Cho JH, Kim SI and Park BW: Elevated levels of preoperative CA 15-3 and CEA serum levels have independently poor prognostic significance in breast cancer. Ann Oncol 24: 1225-1231, 2013.

16. Molina R, Auge JM, Farrus B, Zanón G, Pahisa J, Muñoz M, Torne A, Filella X, Escudero JM, Fernandez P and Velasco M: Prospective Evaluation of carcinoembryonic antigen (CEA) and carbohydrate antigen 15.3 (CA 15.3) in patients with primary locoregional breast cancer. Clin Chem 56: 1148-1157, 2010.

17. Molina R, Auge JM, Escudero JM, Filella X, Zanon G, Pahisa J, Farrus B, Muñoz M and Velasco M: Evaluation of tumor markers (HER-2/neu oncoprotein, CEA, and CA 15.3) in patients with locoregional breast cancer: prognostic value. Tumour Biol 31: $171-180,2010$

18. Nicolini A, Colombini C, Luciani L, Carpi A and Giuliani L: Evaluation of serum CA15-3 determination with CEA and TPA in the post-operative follow-up of breast cancer patients. Br J Cancer 64: 154-158, 1991 .

19. Park BW, Oh JW, Kim JH, Park SH, Kim KS, Kim JH and Lee KS: Preoperative CA 15-3 and CEA serum levels as predictor for breast cancer outcomes. Ann Oncol 19: 675-681, 2008.

20. Samy N, Ragab HM, El Maksoud NA and Shaalan M: Prognostic significance of serum Her2/neu, BCL2, CA15-3 and CEA in breast cancer patients: A short follow-up. Cancer Biomark 6: 63-72, 2010.
21. Wu SG, He ZY, Zhou J, Sun JY, Li FY, Lin Q, Guo L and Lin HX: Serum levels of CEA and CA15-3 in different molecular subtypes and prognostic value in Chinese breast cancer. Breast 23: 88-93, 2014.

22. Ebeling FG, Stieber P, Untch M, Nagel D, Konecny GE, Schmitt UM, Fateh-Moghadam A and Seidel D: Serum CEA and CA $15-3$ as prognostic factors in primary breast cancer. Br J Cancer 86: 1217-1222, 2002.

23. Duffy MJ: Serum tumor markers in breast cancer: Are they of clinical value? Clin Chem 52: 345-351, 2006

24. Darlix A, Lamy PJ, Lopez-Crapez E, Braccini AL, Firmin N, Romieu G, Thezenas S and Jacot W: Serum HER2 extra-cellular domain, S100ß and CA 15-3 levels are independent prognostic factors in metastatic breast cancer patients. BMC Cancer 16: 428 , 2016.

25. Lee JS, Park S, Park JM, Cho JH, Kim SI and Park BW: Elevated levels of serum tumor markers CA 15-3 and CEA are prognostic factors for diagnosis of metastatic breast cancers. Breast Cancer Res Treat 141: 477-484, 2013

26. Nakamura K, Okada E, Ukawa S, Hirata M, Nagai A, Yamagata Z, Kiyohara Y, Muto K, Kamatani Y, Ninomiya T, et al: Characteristics and prognosis of Japanese female breast cancer patients: The BioBank Japan project. J Epidemiol 27: S58-S64, 2017.

27. Nishimiya H, Kosaka Y, Yamashita K, Minatani N, Kikuchi M, Ema A, Nakamura K, Waraya M, Sengoku N, Tanino H, et al: Prognostic significance of Ki-67 in chemotherapy-naive breast cancer patients with 10-year follow-up. Anticancer Res 34: 259-268, 2014

28. Edge SB, Byrd DR, Compton CC, Fritz AG, Greene FL and Trotti A (eds): American Joint Committee on Cancer (AJCC) Cancer Staging Manual. 7th edition. Springer-Verlag, New York, 2010.

29. Howland NK, Driver TD, Sedrak MP, Wen X, Dong W, Hatch S, Eltorky MA and Chao C: Lymph node involvement in immunohistochemistry-based molecular classifications of breast cancer. J Surg Res 185: 697-703, 2013.

30. Goud KI, Dayakar S, Vijayalaxmi K, Babu SJ and Reddy PV: Evaluation of HER-2/neu status in breast cancer specimens using immunohistochemistry (IHC) and fluorescence in-situ hybridization (FISH) assay. Indian J Med Res 135: 312-317, 2012.

31. Zhou P and Recht A: Young age and outcome for women with early-stage invasive breast carcinoma. Cancer 101: 1264-1274, 2004.

32. Zabicki K, Colbert JA, Dominguez FJ, Gadd MA, Hughes KS, Jones JL, Specht MC, Michaelson JS and Smith BL: Breast cancer diagnosis in women $<$ or $=40$ versus 50 to 60 years: Increasing size and stage disparity compared with older women over time. Ann Surg Oncol 13: 1072-1077, 2006.

33. Freedman RA and Partridge AH: Management of breast cancer in very young women. Breast 22 (Suppl 2): S176-S179, 2013.

34. Chung M, Chang HR, Bland KI and Wanebo HJ: Younger women with breast carcinoma have a poorer prognosis than older women. Cancer 77: 97-103, 1996.

35. Wen J, Yang Y, Ye F, Huang X, Li S, Wang Q and Xie X: The preoperative plasma fibrinogen level is an independent prognostic factor for overall survival of breast cancer patients who underwent surgical treatment. Breast 24: 745-750, 2015.

36. Sidoni A, Cavaliere A, Bellezza G, Scheibel M and Bucciarelli E: Breast cancer in young women: Clinicopathological features and biological specificity. Breast 12: 247-250, 2003.

37. Shao Y, Sun X, He Y, Liu C and Liu H: Elevated levels of serum tumor markers CEA and CA15-3 are prognostic parameters for different molecular subtypes of breast cancer. PLoS One 10: e0133830, 2015.

38. Molina R, Zanon G, Filella X, Moreno F, Jo J, Daniels M, Latre ML, Giménez N, Pahisa J, Velasco M, et al: Use of serial carcinoembryonic antigen and CA 15.3 assays in detecting relapses in breast cancer patients. Breast Cancer Res Treat 36: 41-48, 1995.

39. Robertson JF, Jaeger W, Syzmendera JJ, Selby C, Coleman R, Howell A, Winstanley J, Jonssen PE, Bombardieri E, Sainsbury JR, et al: The objective measurement of remission and progression in metastatic breast cancer by use of serum tumour markers. European Group for Serum Tumour Markers in Breast Cancer. Eur J Cancer 35: 47-53, 1999.

40. Sölétormos G, Nielsen D, Schiøler V, Mouridsen H and Dombernowsky P: Monitoring different stages of breast cancer using tumour markers CA 15-3, CEA and TPA. Eur J Cancer 40: 481-486, 2004 
41. Tomlinson IP, Whyman A, Barrett JA and Kremer JK: Tumour marker CA15-3: Possible uses in the routine management of breast cancer. Eur J Cancer 31 A: 899-902, 1995

42. Nieder C, Dalhaug A, Haukland E, Mannsåker B and Pawinski A Tumor marker analyses in patients with brain metastases: Patterns of practice and implications for survival prediction research. Tumour Biol 36: 6471-6476, 2015.

43. James JJ, Evans AJ, Pinder SE, Gutteridge E, Cheung KL, Chan S and Robertson JF: Bone metastases from breast carcinoma: Histopathological-radiological correlations and prognostic features. Br J Cancer 89: 660-665, 2003.

44. Zhao X, Xu X, Zhang Q, Jia Z, Sun S, Zhang J, Wang B, Wang Z and $\mathrm{Hu} \mathrm{X}$ : Prognostic and predictive value of clinical and biochemical factors in breast cancer patients with bone metastases receiving 'metronomic' zoledronic acid. Bmc Cancer 11: 403, 2011.
45. Harris L, Fritsche H, Mennel R, Norton L, Ravdin P, Taube S, Somerfield MR, Hayes DF and Bast RC Jr; American Society of Clinical Oncology: American Society of clinical oncology 2007 update of recommendations for the use of tumor markers in breast cancer. J Clin Oncol 25: 5287-5312, 2007.

46. Bast RC Jr, Ravdin P, Hayes DF, Bates S, Fritsche H Jr, Jessup JM, Kemeny N, Locker GY, Mennel RG and Somerfield MR; American Society of Clinical Oncology Tumor Markers Expert Panel: 2000 update of recommendations for the use of tumor markers in breast and colorectal cancer: Clinical practice guidelines of the American Society of Clinical Oncology. J Clin Oncol 19: 1865-1878, 2001. 